\title{
Lumbar Artery Pseudo-Aneurysm after Spinal Trauma and Transpedicular Fixation: A Case Report
}

\author{
Armel Junior Tokpo, Guelord Metre Mpambia, Fayçal Lakhdar, Hassan Amadou Ali, \\ Oualid Mohammed Hmamouche, Mohammed Benzagmout, Khalid Chakour, \\ Mohammed El Faiz Chaoui \\ Teaching Hospital of Hassan 2, Fès, Morocco \\ Email: armeljuniort@yahoo.com, metreguelord@gmail.com, lakhdar.faycal@gmail.com, hassanem8@gmail.com, \\ oualid.hmamouche@usmba.ac.ma, benzagmout@hotmail.fr, chakour.khalid@yahoo.fr,fmchaoui@yahoo.fr
}

How to cite this paper: Tokpo, A.J., Mpambia, G.M., Lakhdar, F., Ali, H.A., Hmamouche, O.M., Benzagmout, M., Chakour, K. and El Faiz Chaoui, M. (2021) Lumbar Artery Pseudo-Aneurysm after Spinal Trauma and Transpedicular Fixation: A Case Report. Open Journal of Modern Neurosurgery, 11, 65-72.

https://doi.org/10.4236/ojmn.2021.112008

Received: December 31, 2020

Accepted: March 6, 2021

Published: March 9, 2021

Copyright $\odot 2021$ by author(s) and Scientific Research Publishing Inc. This work is licensed under the Creative Commons Attribution International License (CC BY 4.0).

http://creativecommons.org/licenses/by/4.0/

\begin{abstract}
Introduction: A case of lumbar artery pseudo-aneurysm after surgery for lumbar vertebra burst fracture is presented. Only two cases secondary to spinal trauma and revealed after surgery have been described in the literature. A review of literature was conducted and a possible relationship with burst fracture or reduction maneuvers was discussed. Case Presentation: Here, we report a post traumatic lumbar burst facture with incomplete motor deficit of lower limbs after a fall. Surgical reduction and stabilization via posterior approach were performed. Post-operatively, a hemorrhage through surgical wound had been noticed. Pseudo-aneurysm of the lumbar artery at L3 level was diagnosed and embolisation was performed. Conclusion: This is a rare case of pseudo-aneurysm occurring in the setting of surgical stabilisation after a trauma. It was revealed by a hemorrhage discovered as a late complication. We should be aware of such potential complication as a delayed post surgery event in order to adapt the care.
\end{abstract}

\section{Keywords}

Pseudo-Aneurysm, Lumbar Spine, Burst Fracture, Embolisation

\section{Introduction}

Lumbar arteries arise from the dorsal aspect of great vessels and are committed to supplying vertebrae, para spinal and posterior abdominal muscles. There are 5 pairs of lumbar arteries (even if this organisation can present some variations), the first four arising from abdominal aorta; the last one from medial or lateral 
sacral artery or from ilio-lumbar artery [1] [2]. They divide into 3 branches: anterior, posterior and middle. These arteries can be subject to many lesions (infections, tumors or pseudo-aneurysms...).

Pseudo-aneurysms are usually met after a penetrating trauma, rarely following a blunt traumatic mechanism [1]. It can also have iatrogenic origins [3] [4] [5]. Lesions of abdomen, lower limb, pelvic bones and spinal column (as well as transverse process) may also be responsible for lumbar artery injury [6]. The diagnosis is suspected on the appearance of retro peritoneal hemorrhage requiring immediate endovascular repair [7].

The authors described the case of a 30-year-old man, attempted suicide and presented with low back and abdominal pain with paraparesis. Spinal computerized tomography revealed L4 burst fracture (TLICS A4 fracture) with retro pulsed fragment and complete central canal stenosis (Figure 1). Thoracolumbar-pelvic computerized tomography (CT) scan showed a right minimal hemoperitoneum without any evidence of solid organ or visceral injury. No vascular lesion was disclosed at that time. After surgery, delayed hemorrhage through the surgical wound was noticed and L3 lumbar artery pseudo-aneurysm was discovered and excluded.

\section{Case}

A 30 years old man suffering from L4 vertebral fracture was stabilized through a posterior approach. Distraction maneuver was necessary for reduction. Surgery went on without any undesired event. Post operative course was uneventful and a follow-up CT scan on day 4 confirmed the correct position of the screws (Figure 2). On the seventh post operative day, local hematoma was observed (Figure 3). The patient was readmitted in operating room for exploration. A significant uncontrolled left para vertebral hemorrhage was encountered after removing hematoma, from below the left transverse process of L3 (Figure 4). Hemostasis was achieved with gauze packing and immediately after a selective angiography was ran and showed a pseudo-aneurysm of the left lumbar artery at L3 that was immediately embolized (Figure 5). One day later, surgical revision of the operative field was achieved and no evident sources of bleeding were identified. The patient's proceeded well with progressive recovery.

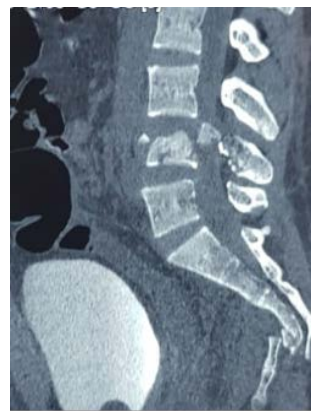

(a)

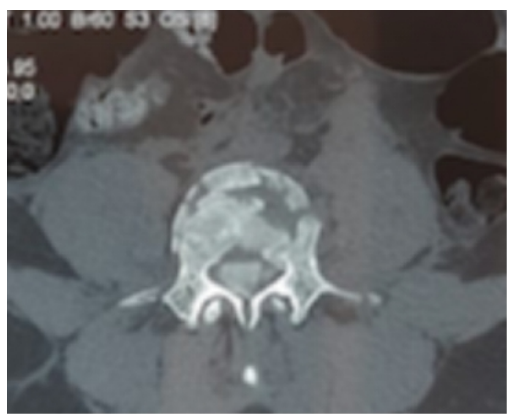

(b)

Figure 1. Sagittal (a) and axial (b) CT image showing lumbar vertebrae fractures. 


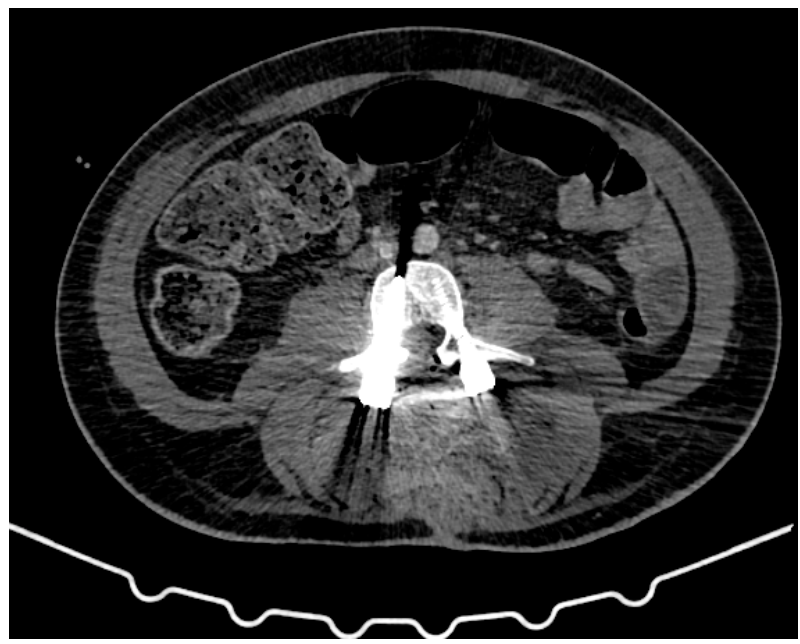

Figure 2. Post-operative axial views of the lumbar spine CT showing intact posterior instrumentation at L3 level without any complications.

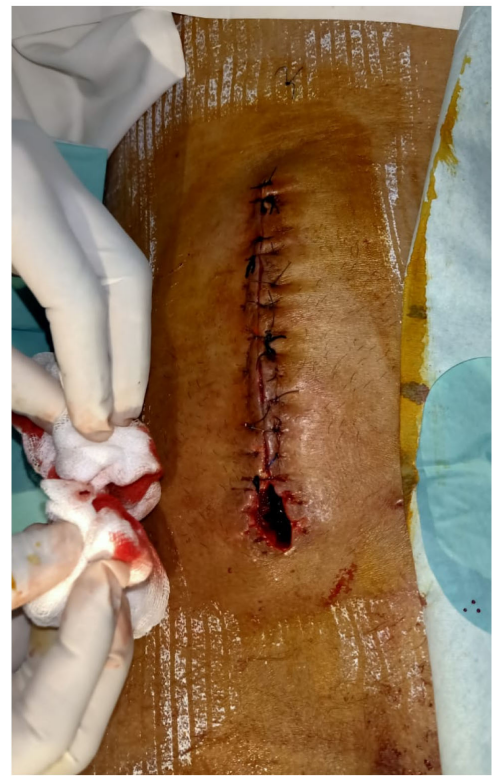

Figure 3. Wound swelling and dehiscence noted after 7 days of surgical procedure.

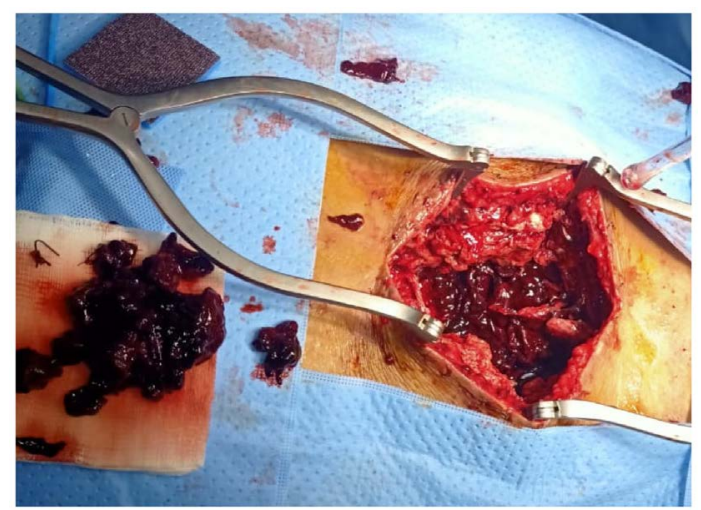

Figure 4. Significant uncontrolled left para vertebral hemorrhage was noticed after removed hematoma. 


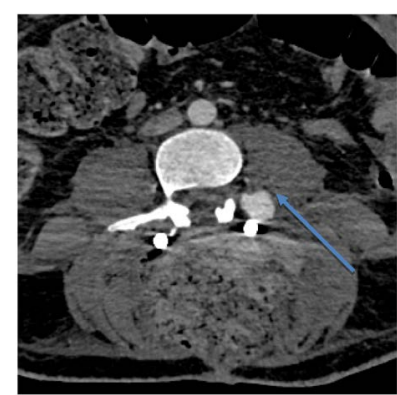

(a)

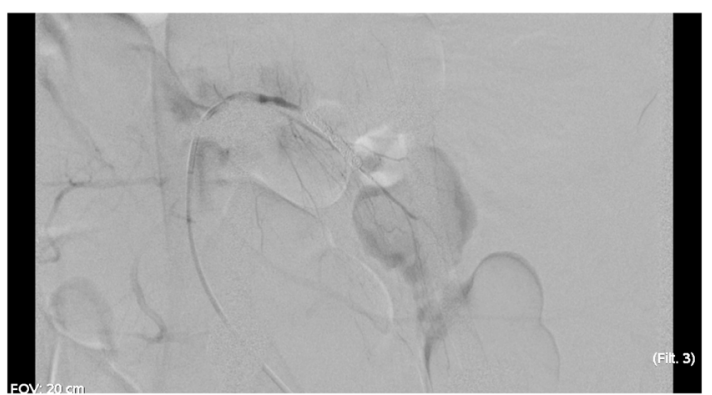

(b)

Figure 5. (a) Left L3 lumbar artery pseudo-aneurysm (blue arrow); (b) Embolisation.

\section{Discussion}

Traumatic injury of a lumbar artery is uncommon: some cases are reported in the literature such as, after renal biopsy [5], blunt trauma [8] or energetic retraction during operations for kidney transplant or gastrectomy [4]. Only few cases of lumbar pseudo-aneurysm after spinal surgery are described in the literature (Table 1).

According to penetrating traumas, Chan et al. in 2003 reported a delayed diagnosis during patient rehabilitation after a spinal cord gunshot injury [9]. Also Kessel, et al. reported a delayed presentation after a penetrating abdominal trauma in 2004. Interestingly, the pseudo-aneurysm was missed during the initial laparotomy [10].

More recently a hypotensive shock following a blunt trauma leads to diagnose a left L4 lumbar artery pseudo-aneurysm [1]. Lee, et al. reported the same clinical status concurrent with a left L2 lumbar artery pseudo-aneurysm due to a transverse process fracture at the same level [11]. So whatever the trauma blunt or penetrating, the diagnosis could be immediate or delayed according to clinical presentation.

Iatrogenic vascular complication (like pseudo-aneurysm formation) after spine surgery accounts for $0.01 \%$ to $0.22 \%$ with a high mortality rate $(15 \%$ 65\%) [12].

In this setting Oh, et al. [13] had reported a right L3 lumbar artery pseudo-aneurysm discovered through a delayed retro peritoneal hematoma. The patient previously underwent a surgical stabilisation of L3 and L4 vertebrae. The pseudo-aneurysm appeared in the vicinity of an iatrogenic right transverse process fracture of $\mathrm{L} 3$.

Another study conducted by Liu et al. [14] had gathered informations about only iatrogenic lumbar artery injuries during spine surgery. They found 26 cases between 1991 and 2018. Clinical patterns were polymorph and various therapeutic procedures were associated (simple canal decompression, vertebral needle biopsy, percutaneous kyphoplasty or vertebroplasty, postero-lateral interbody fusion, pedicle screws...). Also, various causes were suspected. Pedicle screws and distraction maneuvers are one of them. 
Table 1. Published lumbar pseudo-aneurysm arteries.

\begin{tabular}{|c|c|c|c|c|c|c|c|c|}
\hline Auteurs and dates & Patient & $\begin{array}{c}\text { Ages } \\
\text { (years) }\end{array}$ & Sexes & $\begin{array}{c}\text { Primary } \\
\text { disease }\end{array}$ & Symptom & Operation & $\begin{array}{c}\text { Affected } \\
\text { LA }\end{array}$ & Outcome \\
\hline Chan, et al., 2003 & 1 & 24 & M & L3-4 & paraplegia & antibiotics & Left L3 & Cured \\
\hline $\begin{array}{c}\text { Domenicucci, et al., } \\
2008\end{array}$ & 1 & 23 & M & $\mathrm{T} 12-\mathrm{L} 1$ & paraplegia & TPF & Left L1 & Cured \\
\hline Nijenhuis, et al., 2009 & 1 & 69 & M & DL & LBP L4-5 & LF & Right L4 & cured \\
\hline Santillan, et al., 2010 & 1 & 55 & M & L2-L3 & & XLIF & Left L2 & Cured \\
\hline & & 67 & $\mathrm{~F}$ & & & L3-4 VP & Left L3 & Cured \\
\hline Puri, et al., 2011 & 2 & 81 & $\mathrm{~F}$ & $\begin{array}{c}\text { CF T11, } \\
\text { L1-2-3 } \\
\text { \& L5 }\end{array}$ & & VP & Right L3 & Cured \\
\hline Young, et al., 2013 & 1 & 55 & $\mathrm{~F}$ & & LBP & PLF L4-5 & Right L2 & Cured \\
\hline Giordano, et al., 2016 & 1 & 73 & M & RCC & & VP & Left L2 & Cured \\
\hline Latka, et al., 2019 & 1 & 58 & M & & LBP & TPF/PLIF & & Cured \\
\hline Vashisht, et al., 2019 & & & & $\begin{array}{l}\text { L1, } 2,3 \\
\text { et } \mathrm{L} 4\end{array}$ & WBL & & Left L4 & Cured \\
\hline Eissa, et al., 2020 & 1 & 30 & M & $\mathrm{L} 2$ & & TPF & Left L4 & Cured \\
\hline
\end{tabular}

LA: lumbar artery; DL: degenerative lumbar; LBP: lower back pain; TPF: Transpedicle fixation; LF: laminectomy + foraminotomy, VP: vertebroplasty, CF: compression fracture; RCC: renal cell carcinoma, WBL: weakness of bilateral lower limbs.

This study published in 2008 by Domenicucci's team [15] reported a left L1 lumbar artery pseudo-aneurysm. It had been discovered seven days after surgical reduction and stabilisation of a seat-belt fracture at T12-L1. This is somehow the case we're talking about here. Our patient also suffered a blunt trauma with complex fracture of L4 involving both transverse processes. Pedicle screws were implanted without any adverse event and distraction performed to correct the angulation. Also, the CT scan showed correct position of the screws. The left L3 pseudo-aneurysm discovered later is not probably linked to corresponding screw misplacement. We think that the distraction maneuver could somehow stretch a pre existing fragile traumatized vessel. This could probably lead to pseudo-aneurysm formation. This argument of severity of spinal trauma in the occurrence of pseudo-aneurysm is supported by the case published by Saurabh, et al. [1].

In 2020 Abdulah, et al. [16] also reported a case of post operative lumbar artery pseudo-aneurysm in the setting of trauma. The difference here is the fact that authors first ran a CT scan which aid to the diagnosis. Once the pseu- 
do-aneurysm was excluded, surgical exploration took place. Criticizing ourselves, this procedure seems to be more accurate. So the lesson is to rapidly obtain a CT scan in front of a delayed hemorrhage after surgical spine instrumentation in order to rule out a possible threatening arterial pseudo-aneurysm.

Elsewhere [15] it has been postulated that "the lumbar artery may be stretched during severe vertebral dislocation". The damage related to stretching may probably create a breach in the muscular and elastic components of the artery [15]. The probable weakening of the arterial wall associated with intra operative distraction maneuvers probably led to its rupture.

\section{Conclusion}

Delay swelling or hemorrhage from surgical wound after lumbar spine surgery must raise suspicion of rupture of lumbar pseudo-aneurysm. CT scan should normally be the initial investigation. Selective angiography should also be performed as diagnosis and therapeutic purposes.

\section{Acknowledgements}

Not applicable.

\section{Declarations}

Patient was informed and his consent was obtained before submission of this case report.

Approval of Ethic committee of Teaching hospital of Fes has been obtained.

\section{Conflicts of Interest}

No competing interest is to be declared.

\section{Funding}

No funding was obtained for this study.

\section{Authors' Contributions}

All authors have read and approved the manuscript.

GMM: redaction, data, corresponding author;

AJT: redaction, data providing, correction;

FL: correction and consent before submission;

HHA: correction;

$\mathrm{OMH}$ : correction;

MB: approval of submission;

KC: approval of submission;

MEFC: approval of submission.

\section{References}

[1] Vashisht, S., Bachhal, V., Kumar, V. and Kumar, D. (2019) Lumbar Artery Pseu- 
doaneurysm Following Blunt Trauma: A Case Report and Literature Review. Trauma Case Report, 23, Article ID: 100232. https://doi.org/10.1016/j.tcr.2019.100232

[2] Tyler, S., Beveridge, et al. (2015) The Lumbar Arteries and Veins: Quantification of Variable Anatomical Positioning with Application to Retroperitoneal Surgery. Clinical Anatomy, 28, 649-660. https://doi.org/10.1002/ca.22504

[3] Biafora, S.J., Mardjetko, S.M., Butler, J.P., McCarthy, P.L. and Gleason, T.F. (2006) Arterial Injury Following Percutaneous Vertebral Augmentation: A Case Report. Spin, 31, E84-E87. https://doi.org/10.1097/01.brs.0000197596.88416.02

[4] Marty, B., Sanchez, L.A., Wain, R.A., Ohki, T., Marin, M.L., Bakal, C., et al. (1998) Endovascular Treatment of a Ruptured Lumbar Artery Aneurysm: Case Report and Review of the Literature. Annals of Vascular Surgery, 12, 379-383.

https://doi.org/10.1007/s100169900172

[5] Jamison, M.H. and Coward, R.A. (1985) Severe Haemorrhage from a Lumbar Artery as a Complication of Percutaneous Renal Biopsy. Postgraduate Medical Journal, 61, 69-70. https://doi.org/10.1136/pgmj.61.711.69

[6] Patten, R.M., Gunberg, S.R. and Brandenburger, D.K. (2000) Frequency and Importance of Transverse Process Fractures in the Lumbar Vertebrae at Helical Abdominal CT in Patients with Trauma. Radiology, 215, 831-834. https://doi.org/10.1148/radiology.215.3.r00jn27831

[7] Santillan, A., Patsalides, A. and Gobin, Y.P. (2010) Endovascular Embolization of Iatrogenic Lumbar Artery Pseudoaneurysm Following Extreme Lateral Interbody Fusion (XLIF). Vascular and Endovascular Surgery, 44, 601-603. https://doi.org/10.1177/1538574410374655

[8] Peters, M., Henny, C.P., ten Cate, J.W., Marsman, J.W.P. and Breederveld, C. (1984) Lumbar Arterial Rupture Secondary to Iliopsoas Hemorrhage in a Hemophiliac Patient. Acta Haematologica, 71, 128-129. https://doi.org/10.1159/000206571

[9] Chan, K.-T. and Korivi, N. (2003) Lumbar Artery Pseudoaneurysm in Traumatic Spinal Cord Injury: A Case Report. Archives of Physical Medicine and Rehabilitation, 84,455-457. https://doi.org/10.1053/apmr.2003.50029

[10] Kessel, B.J., Habib, F.A., Thompson, B., Bajayo, D.E. and Shatz, D. (2004) Lumbar Artery Pseudoaneurysm. European Journal of Trauma, 30, 187-190. https://doi.org/10.1007/s00068-004-1348-2

[11] Lee, J.S., Kim, C.W. and Suh, K.T. (2008) Lumbar Artery Injury Combined with a Transverse Process Fracture of the Lumbar Spine Presenting with Hypovolemic shock after a fall-A Case Report. The Journal of the Korean Orthopaedic Association, 43, 400-403. https://doi.org/10.4055/jkoa.2008.43.3.400

[12] Latka, K., et al. (2019) Iatrogenic Lumbar Artery Pseudo Aneurysm after Lumbar Transpedicular Fixation: Case Report. Sage, 7, 1-4. https://doi.org/10.1177/2050313X19835344

[13] Oh, Y.M., Choi, H.Y. and Eun, J.P. (2013) Delayed Retroperitoneal Hemorrhage Due to Lumbar Artery Pseudoaneurysm after Lumbar Postero-Lateral Fusion. Journal of Korean Neurosurgical Society, 54, 344-346.

https://doi.org/10.3340/jkns.2013.54.4.344

[14] Liu, L., Li, N., Wang, Q., Wang, H., Wu, Y., Jin, W., et al. (2019) Iatrogenic Lumbar Artery Injury in Spine Surgery: A Literature Review. World Neurosurgery, 122, 266-271. https://doi.org/10.1016/j.wneu.2018.10.219

[15] Domenicucci, M., Ramieri, A., Lenzi, J., Fontana, E. and Martini, S. (2008) Pseudo-Aneurysm of a Lumbar Artery after Flexion-Distraction Injury of the Thoraco-Lumbar Spine and Surgical Realignment: Rupture Treated by Endovascular 
Embolization. Spine, 33, E81-E84. https://doi.org/10.1097/BRS.0b013e3181624b93

[16] Eissa, A.T., Shahbaz, A., Alhelal, F., Alhandi, A., Abaalkhail, M., Aleissa, S., et al. (2020) Postoperative Paralumbar Pseudoaneurysm: A Case Report. Journal of Neurological Surgery Reports, 81, e33-e37. https://doi.org/10.1055/s-0040-1710309

\section{List of Abbreviations}

CT: Computerized tomography;

Hb: Hemoglobin;

T12: Twelfth thoracic vertebra;

TLICS A4: Thoraco-Lumbar Injury;

L1: First lumbar vertebra;

L2: Second lumbar vertebra;

L3: Third lumbar vertebra;

L4: Fourth lumbar vertebra;

L5: Fifth lumbar vertebra;

Min: Minutes. 